УДК 655.3.022.01

\title{
ОБ'ЄКТИВНЕ ЦИФРОВЕ ВИЗНАЧЕННЯ НОРМОВАНИХ РОЗМІРНО-СТРУКТУРНИХ ВЛАСТИВОСТЕЙ ПАПЕРУ ДЛЯ ОФСЕТНОГО ДРУКУ
}

( ) В. Ф. Морфлюк, д.т.н., професор, В. В. Морфлюк-Щур, К.т.н., асистент, С. В. Бендаловський, магістрант, НТУУ “КПІ”, Київ, Україна

\section{Рассмотрена технология цифрового измерения и статисти- ческого определения нормированных размерно-структурных показателей бумаги для офсетного способа печати с применением программно-аппаратных средств с проблемной ориентацией.}

Technology of the digital measuring and statistical determination is considered rationed measuring - structural indexes of paper for the offset method of printing with the use of software and hardware facilities with a problem orientation.

\section{Постановка проблеми}

Якість друкованої продукції залежить від значної кількості факторів впливу на технологічний процес друку та різних властивостей матеріалу, на якому здійснюється друкування, що $€$ однією з задач для поліграфічної галузі та вимагає розробки нових підходів та методів як для стабілізації параметрів технологічного процесу друку, так і для оптимізації процесів аналізу, класифікації та відбору матеріалів для процесу задруковування.

На якість процесу друкування впливають фізичні та оптичні властивості фарби і паперу, вид друкарського обладнання, ступінь автоматизації процесу підготовки та виготовлення продукції, мікроклімат друкарського цеху та інше [1, 2]. Одним з найважливіших аспектів цього про- цесу є вибір матеріалу на якому здійснюється друкування, що особливо стосується найбільш поширеного способу друку офсетного.

Згідно зазначеного, цифрове статистичне визначення та аналіз реальних властивостей паперу та їх класифікація $€$ основною задачею, яка дозволить забезпечити надійність та точність отримання відповідних властивостей офсетного паперу та вибору на ї основі прогнозованих партій офсетного паперу для якісного друкування.

Актуальним рішенням проблеми $€$ автоматизація процесів визначення відповідних властивостей офсетного паперу на основі програмно-апаратних засобів цифрового визначення основних показників (вага та товщина паперу) з статистичною обробкою результатів вимірю- 
вання та аналітичним визначенням пухкості та щільності офсетного паперу 3 застосуванням засобів автоматизації програмування на основі проблемної орієнтації. Застосування засобів з проблемною орієнтацією [3] надає можливість опису процесів вимірювання та аналізу у термінах проблеми, та забезпечують високу точність результатів обробки за рахунок застосування сталої побудови внутрішнього опису програмного забезпечення та швидкої адаптації прикладних програм при зміні алгоритмів аналізу.

Ця концепція дозволяє створити якісно нову інформаційну технологію для визначення нормованих розмірно-структурних властивостей на основі сучасних ЕОМ та дозволяє формувати базу даних експериментальних досліджень партій паперу для офсетного друку.

\section{Аналіз попередніх досліджень}

Сучасні аспекти процесів визначення нормованих розмірно-структурних властивостей паперу для офсетного друку та оптимізації процесів аналізу й класифікації матеріалів для процесу задруковування потребують використання методів цифрового вимірювання та обробки статистичної інформації на основі новітніх програмно-апаратних засобів, 3 застосуванням опису цих процесів на основі проблемної орієнтації, що дозволяє підвищити об'єктивність і точність відбору офсетного паперу для забезпечення якісного друкування.

Аналіз принципів проектування систем визначення нормованих розмірно-структурних властивостей паперу для офсетного друку та тенденцій їх побудови [1, 4, 5] свідчать, що за рахунок автоматизації процесів об'єктивного цифрового визначення властивостей паперу на основі програмного керування 3 цифровою обробкою інформації можливо якісно виконувати аналіз та вибір офсетного паперу для забезпечення прогнозованого функціонування офсетної друкарської машини.

Процес визначення нормованих розмірно-структурних властивостей паперу для офсетного друку потребує статистичної обробки та аналізу ряду властивостей та на їх основі аналітичної обробки для визначення інших властивостей паперу, що повинно забезпечуватися сучасними програмними засобами обробки цифрової інформації.

На основі вищезазначеного, процес визначення властивостей та показників паперу для офсетного друку, які характеризують і забезпечують необхідну якість поліграфічної продукції, пропонується проектувати на основі цифрових систем зі спеціальними програмно-технічними засобами, що забезпечує об'єктивність та надійність відбору необхідної партії паперу для офсетного друку та дозволяє формувати базу даних про виконані експериментальні 
дослідження офсетного паперу для подальшого застосування.

\section{Мета роботи}

Метою статті $€$ розробка концепції побудови системи цифрового вимірювання та статистичного визначення нормованих розмірно-структурних властивостей паперу для офсетного друку із застосуванням програмно-апаратних засобів 3 проблемною орієнтацією.

\section{Результати проведеного дослідження}

Вагомим фактором вибору паперу для офсетного друку для якісного друкування $є$ визначення ряду нормованих розмірноструктурних властивостей паперу [1]: маси паперу площею

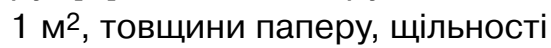
паперу та пухкості паперу.

Сучасні тенденції визначення розмірно-структурних властивостей офсетного паперу базується на основі використання сучасних цифрових систем з використанням спеціальних програмно-технічних засобів, які дозволяють інтегрувати процеси вимірювання, визначення та аналізу у єдину систему вибору офсетного паперу для стабілізації технологічних параметрів процесу друку та формувати базу даних проведених експериментальних досліджень офсетного паперу [2-4].

Автоматизація процесів цифрового визначення нормованих розмірно-структурних показників офсетного паперу проектується на основі статистичної обробки результатів вимірювання маси та товщини паперу, 3 аналітичною обробкою щільності та питомого об'єму офсетного паперу, що забезпечує підвищення точності і достовірності визначення властивостей паперу, які характеризують якість матеріалу для задруковування.

Для функціонування автоматизованої системи визначення нормованих розмірно-структурних властивостей офсетного паперу застосовуються наступні засоби:

- EOM 3 проблемноорієнтованими засобами програмування та обробки інформації;

- електроні вимірювальні прилади для визначення маси та товщини паперу;

- пристрій зв'язку EOM 3 вимірювальними приладами.

Структурна схема цифрової системи визначення нормованих розмірно-структурних властивостей офсетного паперу (рис. 1) складається з ЕОМ, пристрою зв'язку ЕОМ 3 вимірювальними приладами на основі аналого-цифрових перетворювачів (АЦП), призначених для перетворення аналогового значення вихідного сигналу у цифровий код і визначення маси паперу (канал 1) й товщини паперу (канал 2) та проблемноорієнтованих засобів управління, аналізу та статистичного оцінювання властивостей паперу для офсетного друку.

Процес вимірювання маси паперу та товщини паперу будується на основі використання 


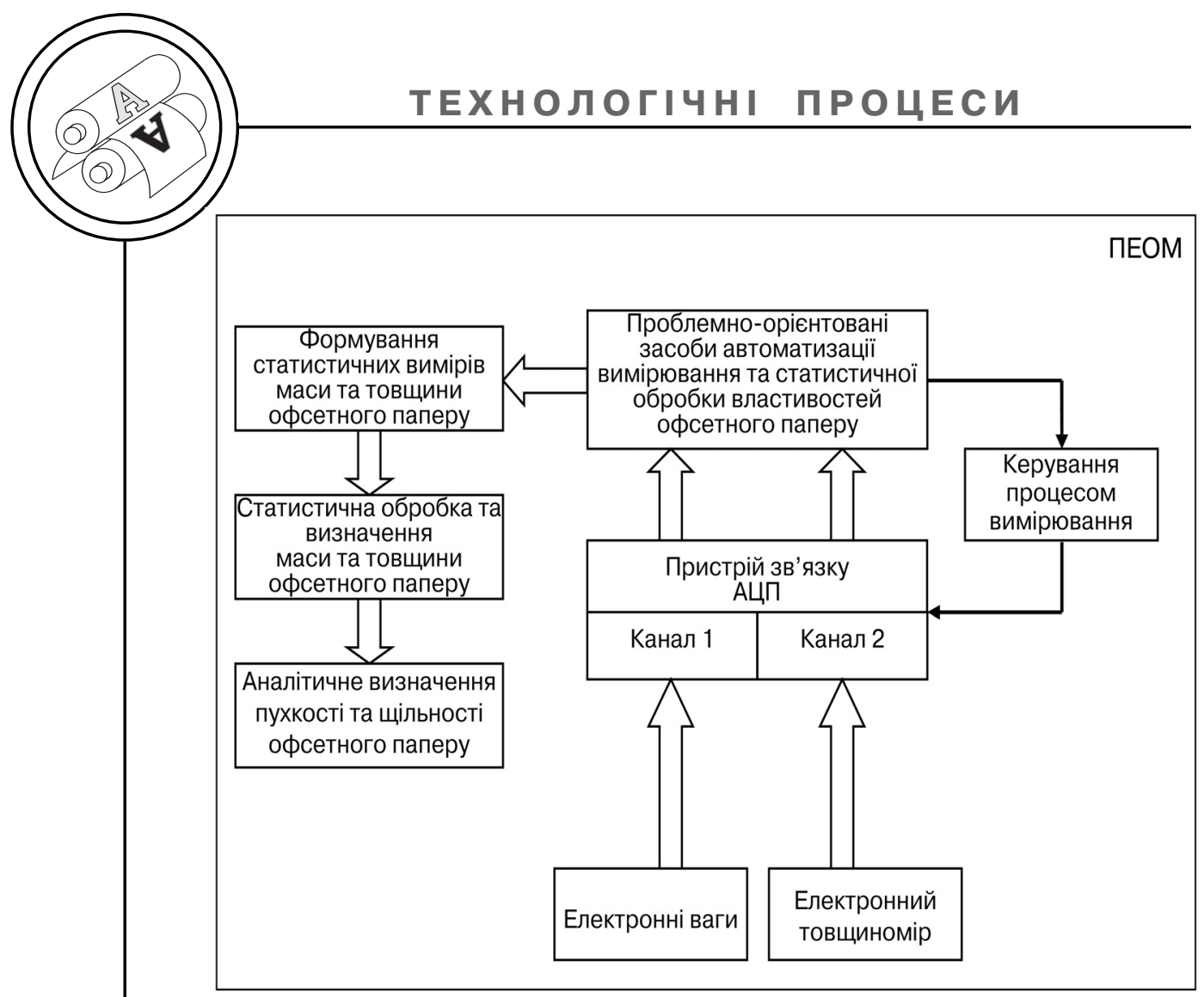

Рис. 1. Структурна схема автоматизації вимірювання та статистичного визначення розмірно-структурних властивостей паперу для офсетного друку

аналогового сигналу з вимірювальних приладів (електронні ваги та електронний товщиномір), який пройшов підсилювання і електричне узгодження, 3 використанням програмноапаратних засобів, керованих EOM.

Вимірювання виконуються за допомогою 12-ти розрядних двійкових АЦП 3 діапазоном вимірюваних вхідних значень напруги від 0 до 2,5 В. У відповідності 3 характеристиками АЦП (пристрій зв'язку ЕТ-1270) обчислюється уніфіковане вхідне значення напруги АЦП з виходу вимірювального приладу $(P)$ для визначення маси па- перу (M) та товщини паперу $(T)$ :

$$
\mathrm{P}=\mathrm{PV} \cdot \mathrm{K}_{\mathrm{AL \Pi}} / 4096,
$$

де $\mathrm{K}_{\text {Ацп }}$ - кількість одиниць АЦП вимірюваного вхідного сигналу; 4096 - максимальна кількість одиниць АЦП; PV - діапазон вхідних значень напруги АЦП (2,5 B).

Враховуючи, що DT діапазон значень товщини, DM діапазон значень маси паперу, a DP діапазон вихідних значень напруги вимірювальних приладів, можна визначити аналітичні залежності для обчислення значення маси паперу (М) та товщини паперу (T): 


$$
\mathrm{T}=\mathrm{DT} \cdot \mathrm{P} / \mathrm{DP}, \mathrm{M}=\mathrm{DM} \cdot \mathrm{P} / \mathrm{DP} .
$$

Модулі вимірювання товщини паперу T.DAT та маси паперу М.DAT паперу для офсетного друку на проблемноорієнтованій мові наведено на рис. 2 та рис. 3 відповідно.

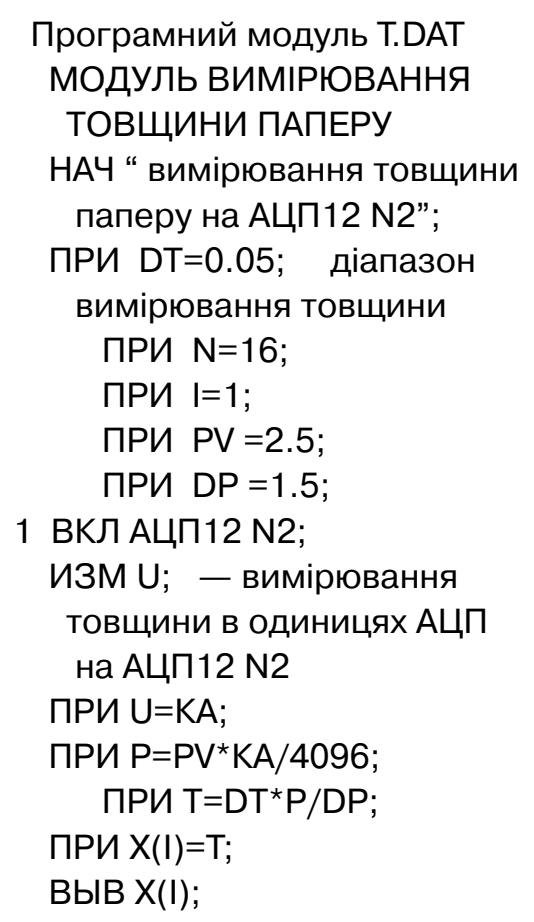

ЗАП Х(І)>Т.ТХТ; формування файлу значень товщини паперу

ПРИ $\mathrm{I}=\mathrm{I}+1$;

ЕСЛ (I >N) ПЕР 5;

ПАУ "ВИМІРЮВАННЯ ЗАКІНЧЕНО - ПРОДОВЖИТИ";

ПEP 1;

5 ВЫВ "Масив значень товщини паперу X(I) та файл T.TXT сформовані";

КОН "ВИМІРЮВАННЯ ЗАКІНЧEHO”;

Рис. 2. Модуль вимірювання товщини паперу
Програмний модуль М.DAT

МОДУЛЬ ВИМІРЮВАННЯ МАСИ ПАПЕРУ

НАЧ " вимірювання маси паперу на АЦП12 N1”;

ПРИ $\mathrm{DM}=50$; діапазон вимірювання маси паперу

ПРИ $\mathrm{N}=16$;

ПРИ I=1;

ПРИ $P V=2.5$;

ПРИ DP $=0.77$;

1 ВКЛ АЦП12 N1;

ИЗМ U; - вимірювання маси паперу в одиницях АЦП на АЦП $12 \mathrm{~N} 1$

ПРИ U=KA;

ПРИ $P=P{ }^{\star} K A / 4096$;

ПРИ $\mathrm{M}=\mathrm{DM}{ }^{\star} \mathrm{P} / \mathrm{DP}$;

$\Pi P И \times(I)=M$;

ВыВ $X(I)$;

ЗАП Х(I)>M.ТХТ; формування файлу значень маси паперу

ПРИ $\mathrm{I}=\mathrm{I}+1$;

ЕСЛ (I >N) ПЕР 5;

ПАУ " ВИМІРЮВАННЯ ЗАКІНЧЕНО - ПРОДОВЖИТИ";

ПEP 1;

5 ВыВ "Масив значень маси паперу X(I) та файл М.TXT сформовані";

КОН "ВИМІРЮВАННЯ ЗАКІНЧEHO “;

Рис. 3. Модуль вимірювання маси паперу

На рис. 4 представлено модуль визначення щільності та питомого об'єму офсетного паперу на проблемно-орієнтованій мові. 


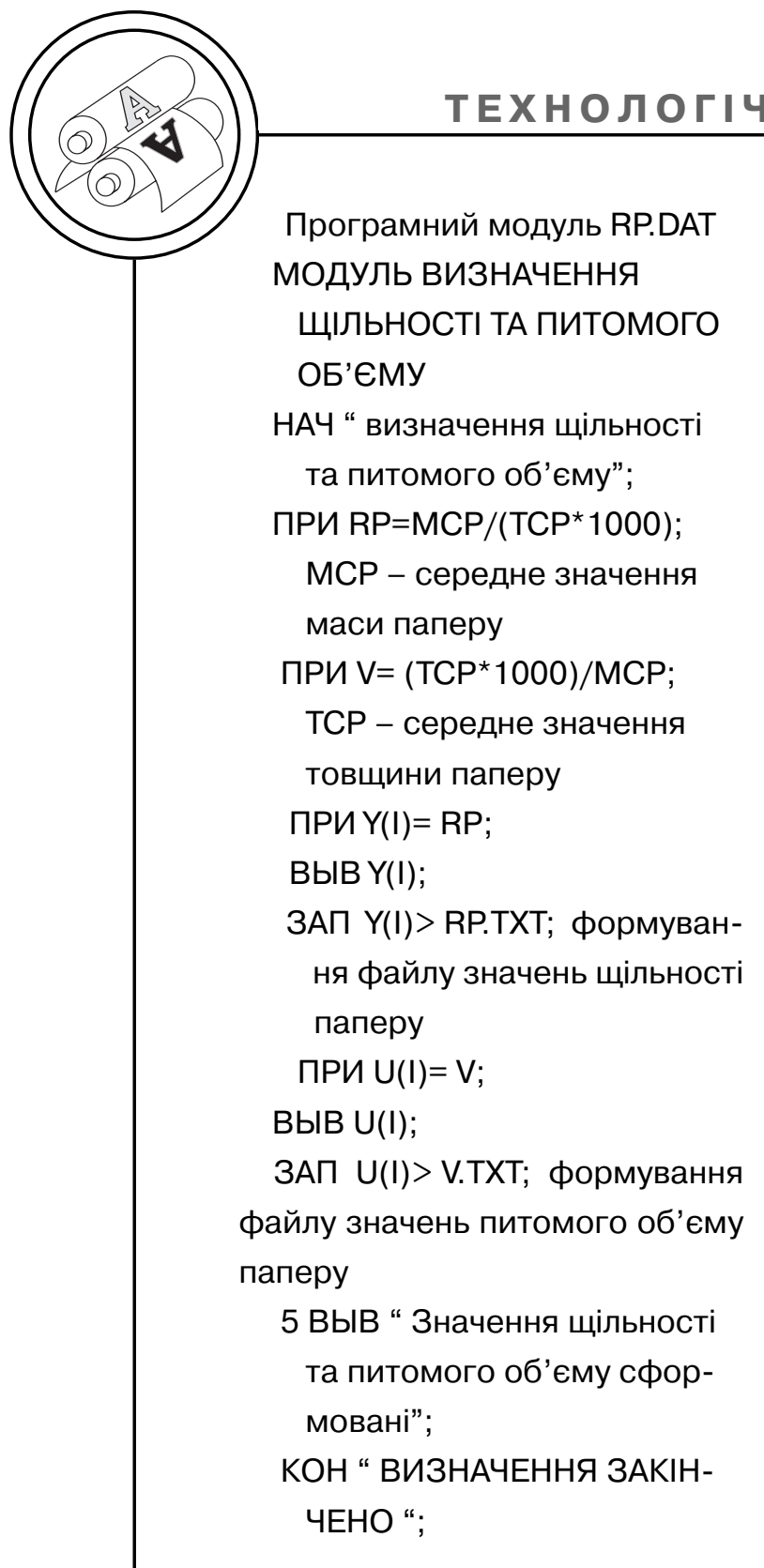

Рис. 4. Модуль визначення щільності та питомого об'єму офсетного паперу

Аналіз достовірності результатів вимірювання базується на методах математичної статистики, які забезпечують статистичне оцінювання властивостей паперу та методі виявлення та усунення випадкових відхилень результатів статистичного вимірювання параметрів.

Для статистичної обробки результатів вимірювання властивостей паперу застосовується уніфікований масив вимірюваних значень X(I) та програмний модуль STAT.DAT на проблемно-орієнтованій мові для об'єктивного статистичного визначення математичного очікування вимірюваних параметрів [4].

Модулі статистичного оцінювання та визначення товщини паперу (STAT_T.DAT), маси папеpy (STAT_M.DAT) аналогічні, за винятком того, що уніфікований масив вихідних значень X(I) заповнюється вимірюваними значеннями відповідних параметрів, а результати обробки записуються відповідно в зовнішні файли Т.ТХТ (файл значень товщини паперу), М.ТХТ (файл значень маси паперу) для подальшого застосування в інших програмних середовищах.

Для організації процесу статистичної обробки параметрів зволожувального розчину та автоматизації процесу формування файлів використовується програмна оболонка W.PRO проблемно-орієнтованих засобів (рис. 5), в якій визначається послідовність виконання програмних модулів на основі транслятора IN100.EXE [3]. 


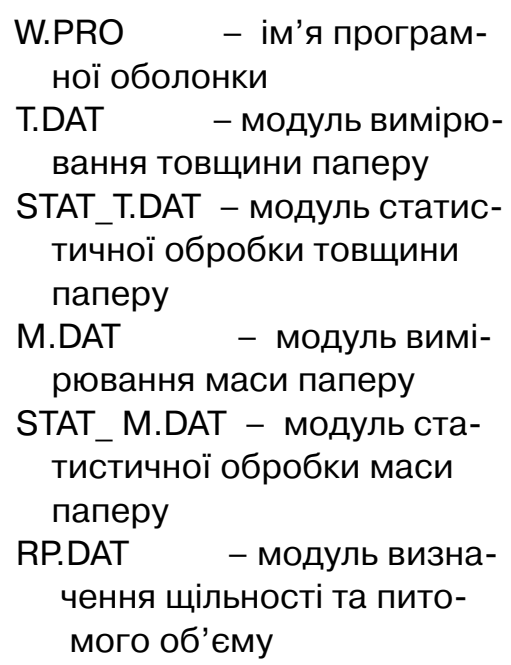

Рис. 5. Програмна оболонка виконання модулів вимірювання та статистичного визначення властивостей паперу

Програмні модулі T.DAT, M.DAT призначені для статистичного вимірювання товщини та маси паперу, модулі STAT_T.DAT, STAT_M.DAT - для статистичної обробки множини вимірів відповідно, а модуль RP.DAT - для визначення щільності та питомого об'єму.

Цифрове статистичне визначення властивостей паперу дозволяє ефективно вирішувати задачі відбору офсетного папе- ру для забезпечення якості друкованої продукції.

\section{Висновки}

1. Інтеграція цифрової технології вимірювання показників паперу для офсетного друку та визначення на основі статистичної обробки результатів експерименту нормованих розмірноструктурних властивостей паперу в єдиній інформаційній базі надає можливість автоматизації технологічного процесу аналізу властивостей офсетного паперу, що забезпечує мінімізацію часу та точність відбору офсетного паперу для забезпечення якості друкованої продукції.

2. Застосування проблемноорієнтованих засобів дозволяє створити якісно нову інформаційну технологію для визначення нормованих розмірноструктурних властивостей паперу на основі сучасних ЕОМ, яка забезпечує об'єктивність та вірогідність результатів вимірювання, а також дозволяє формувати базу даних властивостей відповідних партій паперу для офсетного друку.

1. Глушкова Т. Г. Теоретичні та експериментальні дослідження офсетного паперу зменшеної маси / Т. Г. Глушкова // Товарознавчий вісник : Збірник наукових праць. - Випуск 6. - Луцьк : ЛНТУ, 2013. - С. 27-37. 2. Ефимов М. В. Автоматизированное управление полиграфическим производством / М. В. Ефимов. - М. : Мир книги, 1998. - 416 с. 3. Морфлюк В. Ф. Цифрове визначення та стабілізація параметрів технологічних процесів у рулонних друкарських машинах / В. Ф. Морфлюк. - Київ : ВПЦ «Київська політехніка». - 2008. - 164 с. 4. Морфлюк В. Ф. Автоматизація процесів контролю технологічних параметрів поліграфічного устаткування / В. Ф. Морфлюк // Друкарство. - 2001. - № 1. - С. 34-35. 5. Ефимов М. В. Автоматизация технологических процессов полиграфии / М. В. Ефимов, Г. Д. Толстой. - М. : Книга, 1989. - 512 с. 
1. Hlushkova T. H. Teoretychni ta eksperymentalni doslidzhennia ofsetnoho paperu zmenshenoi masy / T. H. Hlushkova // Tovaroznavchyi visnyk : Zbirnyk naukovykh prats. - Vypusk 6. - Lutsk : LNTU, 2013. - S. 27-37. 2. Efimov M. V. Avtomatizirovannoe upravlenie poligraficheskim proizvodstvom / M. V. Efimov. - M. : Mir knigi, 1998. - 416 s. 3. Morfliuk V. F. Tsyfrove vyznachennia ta stabilizatsiia parametriv tekhnolohichnykh protsesiv u rulonnykh drukarskykh mashynakh / V. F. Morfliuk. - Kyiv : VPTs «Kyivska politekhnika». - 2008. 164 s. 4. Morfliuk V. F. Avtomatyzatsiia protsesiv kontroliu tekhnolohichnykh parametriv polihrafichnoho ustatkuvannia / V. F. Morfliuk // Drukarstvo. 2001. - № 1. - S. 34-35. 5. Efimov M. V. Avtomatizacija tehnologicheskih processov poligrafii / M. V. Efimov, G. D. Tolstoj. - M. : Kniga, 1989. $512 \mathrm{~s}$.

Рецензент - О. В. Зоренко, К.Т.н., доцент, НТУУ «КП।»

Надійшла до редакції 16.12.13 